\title{
VIRTUDES DO CONSTITUCIONALISMO CONTEMPORÂNEO BRASILEIRO: CAUSAS OU CONSEQUÊNCIAS DE UM SISTEMA “GREEN ECONOMY"?
}

\author{
Benedicto Gonçalves Patrão 1 \\ Eric Santos Andrade ${ }^{2}$
}

\section{RESUMO}

O presente trabalho propõe um debate sobre a correlação da política green economy (vivenciada por diversos países europeus) e do modelo das "Cidades Inteligentes" com os novos parâmetros urbanos introduzidos a partir da promulgação da Constituição Federal de 1988; pelas novidades expressas no Estatuto da Cidade e da ascensão municipal enquanto ente federativo. O objetivo é analisá-los partindo do pressuposto de se buscar promover o respeito à diversidade cultural, religiosa, étnica, e etc., de forma a possibilitar uma plena e harmônica convivência social partindo dos preceitos seguidos pela política urbana. Da análise será contrastado tanto o plano teórico quanto pragmático.

Palavras-chaves: Política green economy; Cidades Inteligentes; Sustentabilidade Efetiva; Redemocratização da Política Urbana; Autonomia Municipal.

\section{MERITS OF CONTEMPORARY BRAZILIAN CONSTITUTIONALISM: CAUSES OR CONSEQUENCES OF THE GREEN ECONOMY SYSTEM?}

\begin{abstract}
The present work proposes a debate on the correlation of the green economy policy (experienced by European countries) and the model of the "Smart Cities" with the urban parameters introduced since the promulgation of the Federal Constitution of 1988; by the innovations expressed in the Statute of the City and the county ascent of the federation. The objective is to analyze them based on promoting respect for cultural, religious, ethnic, and other diversitys, in order to enable a ample and harmonious social coexistence based on these urban politics. From the analysis will be contrasted both the theoretical and the pragmatic.
\end{abstract}

Keywords: Green economy policy; Smart Cities; Effective sustainability; Redemocratization of urban policy; Municipal Autonomy.

\section{INTRODUÇÃO}

Zygmunt Bauman (BAUMAN, 2009, p. 37) alerta que a arquitetura das cidades cada vez mais se torna defensiva, diante da crescente necessidade de erigir dispositivos de segurança como subterfúgios ao medo, que atualmente subjuga o ambiente urbano. $\mathrm{O}$ paradigma da "segurança total" (BAUMAN, 2009, p. 38), materializado na necessidade de cercar os espaços, sejam privados ou públicos, através de todos os tipos de formas contra a

\footnotetext{
${ }^{1}$ Doutor em Direito pela UERJ. Professor Adjunto da Universidade Federal Fluminense (UFF). Advogado - email: benedictopatrao@id.uff.br - Tel. (21) 988080848 - http://lattes.cnpq.br/5756015483623650.

2 Mestrando em Direito da Cidade pela UERJ. Advogado - e-mail: ericsantos13@gmail.com - Tel. (22) 999596564 - http://lattes.cnpq.br/1295100572894793.
}

Revista de Direito Urbanístico, Cidade e Alteridade | e-ISSN: 2525-989X | Salvador | v. 4 | n. 1 | p. 19-38 | 
violência, fez com que a liberdade fosse abdicada, em prol de uma fantasiosa sensação de segurança. Estes "enclaves fortificados" (CALDEIRA, 2000, p. 257), requisitos "em todos os tipos de prédios que aspirem a ter prestígio" (CALDEIRA, 2000, p. 261), têm seu exemplo mais marcante nos condomínios de luxo, fazendo com que a natureza do espaço público e a qualidade das interações entre os citadinos tornem-se cada vez mais marcadas pela suspeita e rejeição (CALDEIRA, 2000, p. 259). Desta maneira, modela-se o modo pelo qual os habitantes das cidades contemporâneas interagem entre si, bem como se apropriam do meio em que estão inseridos, através da uniformidade dos bairros residências, em que a redução ao máximo das atividades comerciais e a comunicação entre as diversas partes da cidade (BAUMAN, 2009, p. 50), contribuem para a tendência segregacionista.

Proteger do perigo, como indica Nan Ellin (ELLIN, 2003, p. 43-61), sempre esteve entre os principais estímulos para construir cidades, cujos arrabaldes - das antigas aldeias mesopotâmicas, às aldeias dos nativos norte-americanos - eram definidos muitas vezes por extensos muros e cercas, que estremavam o limite em que os inimigos eram mantidos do outro lado, evitando-se indesejáveis aproximações. Hoje, contudo, perpetra-se o milenar vínculo entre civilização e barbárie (DIKEN; LAUSTSEN, 2002, p. 290), a partir do momento em que o convívio no espaço urbano tem como característica a onipresença do medo, a partir da perspectiva de que as fontes do perigo, diferentemente daquilo que ocorria nos primórdios da urbanização, atingem o coração da cidade, em que a amalgamação de "amigos" e "inimigos" se confundem nos espaços comuns de convivência.

Portanto, segundo Bauman, presencia-se uma guerra à insegurança, em curso dentro da cidade, "cujo baluarte defensivo é representado pelas gated communities, com os indefectíveis guardas armados e câmaras de controle" (BAUMAN, 2009, p. 62). O espaço público foi a primeira vítima colateral de uma cidade que perde a árdua luta enfrentada para resistir ao avanço do isolamento espacial dos moradores (BAUMAN, 2009, p. 66), já que a guerra à insegurança tem primazia na lista de prioridades dos planejadores urbanos. No entanto, ao manter e tornar forte a tendência excludente, podemos até atenuar, nas palavras do sociólogo polonês, "o padecimento daqueles que sofrem com a mixofobia ${ }^{3}$, mas o remédio é por si mesmo patogênico e torna mais profundo o tormento, de modo que - para mantê-lo sob controle - é preciso aumentar continuamente as doses", fazendo com que a vida pareça ainda

${ }^{3}$ Bauman faz a distinção entre mixofobia, que seria o receio de estar na presença física com desconhecidos, e mixofilia, que seria, ao contrário, a experiência prazerosa de convivência com estranhos (BAUMAN, 2009, p. 35).

Revista de Direito Urbanístico, Cidade e Alteridade | e-ISSN: 2525-989X | Salvador | v. 4 | n. 1 | p. 19 - 38 | 
mais angustiantemente propensa ao perigo, em vez de mostrá-la segura e prazerosa. Nisto, a opção pelas gated communities fez desaparecer das ruas da cidade a "espontaneidade, a flexibilidade, a capacidade de surpreender e a oferta de aventura, em suma, todos os atrativos da vida urbana" (BAUMAN, 2009, p. 68), razão pela qual o planejamento, como forma de proteção ao sentimento "mixófilo", deveria adotar estratégia oposta, ou seja, difundir os espaços públicos abertos, que são mais convidativos e acolhedores aos cidadãos que tenham vontade de frequentar espontaneamente. Afinal, como nos ensina Hans-Georg Gadamer (GADAMER, 1997, p. 25), compreensão recíproca é sempre um processo de fusão dos horizontes, traçados e ampliados acumulando-se experiências de vida, que só se concretizará por meio da experiência compartilhada, que é inimaginável sem a possibilidade de partilhar um espaço.

Neste sentido, o espaço, de uso público e multifuncional ${ }^{4}$ - identificado como os locais tradicionais de uso comum nas cidades, tais como ruas, praças, calçadas, e parques ganha relevante destaque na formação da criança e do adolescente, já que, estando impedidos de frequentar o ambiente comunitário, em razão da desordem citadina ${ }^{5}$, os mesmos deixam de observar as mudanças que ocorrem na cidade como um todo. Isto tem efeitos devastadores na própria dinâmica urbana, pois se deve entender e sentir a cidade através de seus espaços de uso comum ${ }^{6}$, de tal forma que, quanto mais diversificado for a utilização dos logradouros, praças, calçadas e parques, através da apropriação do local público ${ }^{7}$, mais seguro e propício à convivência os mesmos se tornam ${ }^{8}$.

\footnotetext{
${ }^{4}$ A multifuncionalidade da cidade é um princípio informador da mesma, na medida em que a cidade acolhe simultaneamente várias funções complexas, desenvolvendo uma pluralidade de diferenças (diferentes culturas, tipologias de ocupação de espaço urbano, classes sociais, idades e vulnerabilidades, profissões e ofícios).

5 "No Brasil, a urbanização intensiva já transformou estruturalmente a ordem socioeconômica e redesenhou a ocupação do território nacional, tendo provocado impactos ambientais comparáveis aos efeitos de grandes catástrofes naturais. Cerca de $80 \%$ da população brasileira - de um total de 165 milhões - vive atualmente nas cidades, sobretudo nas áreas metropolitanas" (FERNANDES, 2000, p. 37).

${ }^{6}$ Para Jane Jacobs, a imagem que temos em relação à determinada cidade é diretamente proporcional àquilo que apreendemos de suas ruas. Assim sendo, "se as ruas de uma cidade parecem interessantes, a cidade parecerá interessante; se elas parecerem monótonas, a cidade parecerá monótona" (JACOBS, 2003, p. 29).

${ }^{7}$ Segundo Jacobs, a existência de um número substancial de estabelecimentos e outros locais públicos, dispostos ao longo das calçadas, é um requisito básico de vigilância, acarretando em maior segurança, na medida em que permite que as pessoas, tanto moradores, quanto estranhos, tenham motivos concretos para utilizar os locais onde esses estabelecimentos se encontram (JACOBS, 2003, p.30).

${ }^{8}$ Jacobs aponta, como traço característico das cidades, o fato de estarem sempre repletas de estranhos, afirmando que os mesmos são benéficos, fazendo a cidade mais divertida, desde que a rua esteja bem preparada para lidar com eles, através de uma boa e eficaz demarcação de áreas provadas e públicas e um "suprimento básico de atividades e olhos" (JACOBS, 2003, p. 41).
}

Revista de Direito Urbanístico, Cidade e Alteridade | e-ISSN: 2525-989X | Salvador | v. 4 | n. 1 | p. 19-38 | 
São nestes espaços de convivência social que os cidadãos, ao interagirem com outros e de diferentes crenças, etnias e classes sociais, aprendem a se relacionar e a respeitar as regras de convívio, em especial a solidariedade. Espera-se que a busca pelo usufruto equitativo do ambiente urbano, alcançado pela tutela dos elementos que compõem o direito à cidade afiançará o ideal de convívio articulado de ambos os lados da "cidade partida". Para tanto, o Poder Público, em especial o Município, principal ente federativo responsável pela gestão urbana ${ }^{10}$, e o Ministério das Cidades, a nível federal, ganham especial destaque.

Sob este último aspecto, portanto, é que o presente trabalho será desenvolvido, ao pretender abordar a importância do Poder Público na institucionalização das políticas públicas de combate às questões urbanas. Afinal, para ser alcançado o ideal de qualidade de vida imposto por nosso ordenamento jurídico, fundado no princípio da dignidade humana (art. $1^{\circ}$, inc. III, da CF/88), é de suma importância compreender a nova ordem jurídico-urbanística nacional, desenvolvida através da democratização do processo decisório, em que a descentralização das políticas públicas, com o fortalecimento dos Municípios, ganha relevante destaque. Além do mais, a consolidação do Ministério das Cidades, ao ocupar um vazio institucional que retirava o Governo Federal da discussão sobre a política pública e o destino dos centros urbanos, pode ser, da mesma forma, considerada uma importante iniciativa na mitigação dos fatos impeditivos da fruição do espaço, inaugurando um novo padrão no planejamento das cidades.

\section{1- A ESTRUTURA DA POLÍtiCA URBANA NA LEGALIDADE CONSTITUCIONAL}

Diante do quadro de incertezas acarretadas pelo atual estado de desordem citadina, percebe-se a nítida e necessária interação existente entre urbanismo e Direito, em razão de o segundo resguardar sempre um alto grau de interferência no planejamento das cidades, a fim

\footnotetext{
${ }^{9}$ A expressão "Cidade Partida" foi criada pelo jornalista Zuenir Ventura, em sua obra homônima. O abismo entre a favela e o resto da sociedade vai assim se alargando, na medida em que um lado, cada vez mais, conhece menos o outro e se relaciona com ele do jeito que o estereótipo o orienta.

${ }^{10}$ A atuação de cada ente é definida pelas competências estabelecidas pela própria Carta Magna. Em nosso sistema constitucional, aos Municípios compete legislar sobre assuntos de interesse local, suplementar a legislação federal e estadual no que couber, promover o adequado ordenamento territorial mediante planejamento e controle do uso, do parcelamento e da ocupação do solo urbano, promover a proteção do patrimônio histórico-cultural local, observadas a legislação e a ação fiscalizadora federal e estadual, executar a política de desenvolvimento urbano e elaborar o Plano Diretor.
}

Revista de Direito Urbanístico, Cidade e Alteridade | e-ISSN: 2525-989X | Salvador | v. 4 | n. 1 | p. 19 - 38 | 
de alcançar o objetivo constitucional de proteção da dignidade humana, alcançável por meio do desenvolvimento urbano sustentável. No caso, sob o âmbito do Direito Urbanístico, tal escopo somente será concretizado mediante regras de ordem pública voltadas para a ordenação urbana, especialmente, na limitação ao uso da propriedade, em que as atividades que possam causar danos à comunidade urbana são controladas, disciplinando-se, por exemplo, a efetivação de políticas públicas voltadas para a construção do ambiente citadino sustentável.

Isso se deve ao fato de que o artigo 182 da CRFB/88 estabelece que a política de desenvolvimento urbano deve ter como meta ordenar o pleno desenvolvimento das funções sociais da cidade a fim de garantir o bem-estar de seus habitantes, cabendo ao Estatuto da Cidade (Lei 10.257/01) o dever de fixar diretrizes gerais, que visem à efetivação de tal objetivo constitucionalmente tutelado. Afinal, o ambiente público tem como designo estabelecer redes de interação social e as cidades têm como fundamento a amalgamação de indivíduos, sendo a segregação socioespacial um desvirtuamento de tal fim. Somando-se a isso, os espaços públicos de convivência são essenciais para o desenvolvimento da cidadania e o esvanecimento dos ambientes públicos de convivência urbana trazem prejuízos nefastos para a vida em sociedade.

O estabelecimento de condições propícias para a convivência comunitária dos cidadãos - compreendida como o usufruto do espaço convivial, em especial no ambiente público - está inserido na noção de função social da cidade. Assim, constitui objeto de preocupação do Estatuto da Cidade e do Plano Diretor, que devem pautar a utilização dos instrumentos de política urbana, essenciais na concretização do desenvolvimento urbano sustentável, para o estabelecimento do ambiente de convivência comunitária.

Além do mais, a política de desenvolvimento urbano, conforme estabelecida no artigo 182 da CRFB/88, deve ser executada pelo poder público municipal, na conformidade das diretrizes fixadas pelo Estatuto da Cidade. Destaca-se o papel do Município, diante de sua inata destreza na busca pelo desenvolvimento de políticas públicas que, na conformidade dos ditames impostos pelas normas de caráter urbanístico, salvaguardam o espaço público de convivência. Portanto, conforme estabelecido pela Carta constitucional, o município, tendo como princípios informadores a centralidade e a diversidade ${ }^{11}$, tem incontroversa vocação ${ }^{12}$,

\footnotetext{
${ }^{11}$ Conforme ensina José Nilo de Castro, "a cidade e o cidadão têm uma integração sensível e sentida. A cidade reage à medida da provocação do cidadão pela força de seus princípios informadores, que são os da centralidade e da diversidade. Informa a cidade o princípio da centralidade, porque é a cidade o centro de tudo, Revista de Direito Urbanístico, Cidade e Alteridade | e-ISSN: 2525-989X | Salvador | v. 4 | n. 1 | p. 19-38 | 
tanto legal como natural, para ser o gestor do espaço e atuar no planejamento das cidades, em cooperação com as diversas associações representativas existentes na municipalidade.

Como vocação natural, qualquer projeto que vise superar o caos urbano deve apresentar plena consciência da natureza e da dinâmica dos locais onde se concentram os problemas de uma determinada cidade. Por isso, a proximidade do gestor municipal justifica a opção pela descentralização das políticas públicas de planejamento urbano. Quanto à vocação legal, destaca-se que a questão envolvendo a tutela do espaço urbano está inegavelmente baseada na obrigatoriedade do município em efetivar soluções voltadas para a revitalização e a readequação dos espaços que sirvam para resguardar a qualidade de vida da criança e do adolescente. Para tanto, utilizam-se as normas urbanísticas, sejam de origem constitucional (por meio dos arts. 182 e 183, ambos da CRFB/88), ou infraconstitucional - em especial, o Estatuto da Cidade (Lei $\left.\mathrm{n}^{\circ} 10.257 / 01\right)$ - no intuito de alcançar o pleno desenvolvimento das funções sociais da cidade.

Afirma-se que o novo paradigma no planejamento da cidade esteja precisamente no fortalecimento das instituições locais, a partir do desenvolvimento in loco de políticas públicas para o planejamento e desenvolvimento, que visam à superação da pobreza e demais problemas que, de alguma forma, comprometem a sobrevivência digna das crianças e dos adolescentes no ambiente urbano. Nisso, resta claro o papel do município em garantir tudo aquilo necessário à gestão da cidade, por meio de prestações positivas que possam ofertar direitos sociais mínimos, sem os quais a criança e o adolescente não têm condições de sobreviver com dignidade.

centro administrativo, centro político, centro religioso, centro econômico-financeiro, centro cultural. Há seguramente aí uma força centrípeta irresistivel. A informar a cidade está o princípio da diversidade, porque nela se situa e se desenvolve pluralidade e raças e de etnias, de profissões e de religiões, de culturas e de trocas de informações" (CASTRO, 2006, p. 379).

${ }^{12}$ Diante daquilo denominado Neolocalismo (CASTRO, 2006, p. 386), o município, como gestor das políticas públicas locais, ganha especial destaque. Conforme afirmado por Marcos André B. C. de Mello, "na realidade, a ideia de descentralização é hoje lugar comum tanto em uma agenda neoliberal quanto em uma agenda histórica, identificada com a social democracia [...]. Dentro de uma tradição neoliberal, a ideia da descentralização, da devolução de funções e competências a entes subnacionais, equivale a uma estratégia maior de retirada de parcela do poder do Governo central. Este é o Leitmotiv da ideia da descentralização. Da mesma forma, dentro de uma agenda social democrática, histórica, a ideia de descentralização é inteiramente diversa; aqueles que propugnam pela descentralização e pela autonomia local, em última instância, estão postulando a democratização da gestão e a ampliação do controle social" (MELO, 1999, p. 65).

Revista de Direito Urbanístico, Cidade e Alteridade | e-ISSN: 2525-989X | Salvador | v. 4 | n. 1 | p. 19 - 38 | 
Contudo a atuação do município não é hermética, ao contrário, exige-se a cooperação das diversas associações representativas ${ }^{13} \mathrm{e}$, inclusive, dos demais entes federativos. ${ }^{14}$ Nesse sentido, a criação do Ministério da Cidade vem ao encontro dessa perspectiva, ao tentar garantir o direito à cidade, por meio do fomento de uma política nacional de desenvolvimento urbano, que visa a fornecer o adequado suporte institucional à efetiva implementação do Estatuto da Cidade. Considera-se a criação do Ministério das Cidades, portanto, um importante marco na estruturação da política urbana, porque introduz o governo federal na discussão sobre o destino das cidades (conforme entrevista realizada pela Erminia Terezinha Menon Maricato).

Por meio da municipalidade, transmuta-se o antigo paradigma da elaboração de planos e projetos a partir dos níveis superiores da representação política, de viés tecnocrático e excludente da participação local e popular, pela primazia do planejamento municipal, baseado na gestão democrática, em cooperação com os demais entes da federação. Já com o Governo Federal, por meio do Ministério da Cidade, que visa fomentar políticas públicas centradas na melhoria das condições de habitação, saneamento ambiental (água, esgoto, drenagem e coleta e destinação de resíduos sólidos) e mobilidade urbana (trânsito), conferemse diretrizes e bases institucionais para a melhoria das condições condignas de utilização do espaço público em prol da superação do atual quadro segregacionista.

Com efeito, ao destacar que a política urbana no Brasil depende essencialmente de um esforço de cooperação federativa - observando o primado da gestão democrática das cidades - é incontroverso que o planejamento das cidades constitui um ato estruturado de mobilização entre os entes da federação e os vários segmentos da sociedade. Contribuir-se-ia, com isso, para a boa governança, ao destacar a legitimidade e relevância do Ministério das Cidades na elaboração de diretrizes gerais e suporte institucional, além de promover a inclusão da criança e do adolescente no espaço de convivência pública, por meio da

${ }^{13}$ O Artigo 29, XII, da Constituição Federal, estabelece que seja princípio básico, a ser inserido na Lei Orgânica do Município, a "cooperação das associações representativas no planejamento municipal".

${ }^{14}$ A doutrina discute se o município tem natureza de ente federativo. José Afonso da Silva é árduo defensor de que o município não se enquadra na Federação dizendo: "Não existe federação de municípios. Existe Federação de Estados". (SILVA, 2007, p. 640). Neste sentido, os autores justificam que, como os municípios não possuem representação no Senado Federal, um Poder Judiciário próprio e até território (uma vez que integram os Estados), não se caracterizam como entes federativos. Por outro lado, o mestre Celso Ribeiro Bastos (BASTOS, 1989, p. 276), arrimado em Hely Lopes Meireles (MEIRELLES, 1989, p. 42), demonstra que o município, devido a importância que destaca na federação, tem, certamente, natureza de ente federativo. Estamos com os últimos. Basta a verificação do art. 18 da nossa Constituição para notar que o Município é uma entidade federativa. Assim, o Município tendo autonomia constitucional, não deve de ser excluído da Federação. Havendo repartição de competências, com a finalidade de garantir a harmonia e o pacto federativo.

Revista de Direito Urbanístico, Cidade e Alteridade | e-ISSN: 2525-989X | Salvador | v. 4 | n. 1 | p. 19 - 38 | 
articulação, implantação e implementação - em parceria com todas as esferas do Poder Público e com a sociedade - de programas e ações destinados a universalizar o acesso da população à habitação digna, ao saneamento ambiental e à mobilidade por meio da racionalização do trânsito e do transporte público.

\section{2 - DA ASCENSÃO MUNICIPAL E SEU PAPEL DESENVOLVIDO SOB A MANTA DAS “CIDADES EDUCADORAS”.}

A neoconstitucionalização iniciada a partir do ano de 1988 e a reorganização de diversos parâmetros jurídicos, dentre eles as questões urbanísticas, são o marco da chamada ascensão municipal enquanto parte integrante dos entes federativos do Brasil. Paulo Bonavides ressalta que não houve em nenhum outro momento uma União Federativa tão expressiva onde o princípio da autonomia municipal tenha alcançado tamanho grau político e administrativo que não seja a Constituição Federal de 1988 (BONAVIDES, 1996, p. 314). Passamos, portanto, a analisar a questão da autonomia dos governos municipais frente ao federalismo brasileiro.

Com o advento da Carta Magna de 1988, também conhecida como Constituição Cidadã, tem-se o início do processo da redemocratização política e social do País. Até então, em 1967, com uma Constituição oriunda de golpe militar, houve enfraquecimento dessa forma de Estado. Com o advento da crise política na segunda metade de 1968, por meio do Ato Institucional 5, foi totalmente extinta a Federação. Com a Carta de 1969, formalmente EC1/67, percebe-se indiscutivelmente a preeminência da União frente aos Estados e Municípios, que, cada vez mais, viam diminuir suas prerrogativas, embora se mantivesse a forma federativa (BASTOS, 1995b, p. 5).

A partir de $1988^{15}$ as mudanças políticas sofridas pelo País mudaram esta realidade com a inclusão dos governos municipais na qualidade de entes federativos. Por conta do processo de redemocratização urbana e de descentralização das políticas sociais os municípios ganharam importante destaque funcional na garantia dos direitos fundamentais dos cidadãos.

Para que tudo isso fosse possível haveria de se ter um relevante motivo para atribuir autonomia aos municípios, isto é, sua relevância no primeiro contato com a sociedade. A

\footnotetext{
${ }^{15}$ Art. 18 da CFRB/88. A organização político-administrativa da República Federativa do Brasil compreende a União, os Estados, o Distrito Federal e os Municípios, todos autônomos, nos termos desta Constituição.

Revista de Direito Urbanístico, Cidade e Alteridade | e-ISSN: 2525-989X | Salvador | v. 4 | n. 1 | p. 19 - 38 | 
questão de se promover uma descentralização política ${ }^{16}$ em benefício de uma democracia viva e eficaz, de uma realidade marcada pela difusão dos direitos sociais e de uma maior força as diretrizes urbanas foram essenciais para conquista municipal de seu lugar dentre os entes federais do Brasil.

Corroborando esse entendimento, Celso Ribeiro Bastos instrui que "o Município é contemplado como peça estrutural do regime federativo brasileiro pelo Texto Constitucional vigente" (BASTOS, 1989, p. 276); Alexandre de Moraes aduz que “a Constituição Federal consagrou o Município como entidade federativa indispensável ao nosso sistema federativo, integrando-o na organização político-administrativa e garantindo-lhe plena autonomia" (MORAES, 2008, p. 276); e Nelson Nery Costa, por sua vez, defende que "o Município, em razão da Constituição Federal, promulgada em 05/10/1988, sofreu profunda transformação, elevando-se num novo patamar como entidade pública. (...) O primeiro e mais significativo aspecto foi colocá-lo formalmente como integrante da Federação Brasileira" (COSTA, 2000, p. 52).

Com a repartição de deveres entre os entes, conservando-se a sua autonomia, é exultado o princípio do pacto federativo ${ }^{17}$. Diante da cooperação pré-existente entre os entes, a União permaneceu com um maior controle dos ditames sociais, mas respeitando a autonomia dos municípios e dos estados.

Ainda, contrastasse o princípio do pacto federativo juntamente com o princípio da indissolubilidade, haja vista que também este repercute aos municípios diante de sua ascensão. O Brasil, portanto, é um Estado Federal, em que a União, os estados e os municípios, apresentando-se igualmente autônomos, preenchem, no âmbito jurídico, o mesmo plano hierárquico, devendo, por conseguinte, auferir tratamento jurídico-formal homogêneo.

16 "Essa etapa foi marcada pelo que passou a ser definido como "coordenação federativa”, situação em que a União passou a ter maior controle sobre o desenho institucional das políticas sociais, mas respeitando a autonomia política de estados e municípios, que não poderiam ser obrigados a aderir às políticas formuladas pela União" (AIETA; GARCIA; LEITE, 2016, p. 17).

${ }^{17}$ Nagib Staibi Filho nos traz de forma simples o contexto aonde se apresenta o princípio do pacto federativo: "Descentralizando o poder de decisão estatal, em cada função e através de diversos níveis territoriais, o que é rigidamente previsto na Constituição, o sistema federativo tem a vantagem de permitir que as forças políticas, econômicas e sociais, em determinada região, não sejam asfixiadas". Significa dizer que quando centralizamos o poder, além do necessário, para um dos entes em detrimentos dos demais, materializa formas flagrantes de agressão ao pacto federativo, contrariando o disposto no artigo 18 da CFRB/88. Portanto, o princípio do Pacto Federativo conceitua-se enquanto a forma de organização fundamental do Estado que é o Federalismo, isto é, fruto da descentralização política (FILHO, 2004, p. 804).

Revista de Direito Urbanístico, Cidade e Alteridade | e-ISSN: 2525-989X | Salvador | v. 4 | n. 1 | p. 19 - 38 | 
A nossa federação é indissolúvel, não podendo nenhum dos entes (União, Estados, Distrito Federal e Municípios) virem a romper com o pacto federativo. E por ser uma cláusula pétrea expressa $\left(\mathrm{CF}\right.$, art. $\left.60 \S 4^{\circ}\right)$, não é possível que uma emenda constitucional que possa vir a dissolver a federação ou ofender o pacto federativo (autonomia dos entes federados). As finalidades básicas do princípio da indissolubilidade do vínculo federativo são a unidade nacional e a necessidade descentralizadora. Os Estados e Municípios não podem se separar do vínculo federativo, eles não possuem essa autonomia frente a proteção da integridade nacional $^{18}$, vedando-se a chamada secessão. (BARROSO, 2015, p. 89-95)

A professora Angela Moulin discute o tema explicando que vivenciamos hoje um contexto no qual os governos municipais foram elevados ao status de "ente federativo" quando o federalismo brasileiro se transformou em um tripartite (União, estados e municípios). Como foi dito anteriormente, há relevante motivo para que consolidasse tamanha descentralização, uma delas é o almejo pela descentralização ${ }^{19}$ de poder e a implementação de uma democracia eficaz, a segunda se justifica na medida em que os municípios são instituições que mais possuem contato direto com a sociedade. Dessa forma, a fiscalização e promoção, principalmente de política públicas urbanas e sociais, estariam mais resguardadas quando sob o comando destes agentes.

Não muito longe ainda discute-se sobre os reflexos trazidos pelo processo de descentralização do poder. Celso Ribeiro Bastos traz uma subdivisão em descentralização administrativa e política adotando o critério da extensão dos poderes atribuídos às circunscrições territoriais. O raciocínio, segundo o autor, é de que ao levarmos em consideração que a descentralização administrativa confere liberdade para se eleger os próprios representantes e de promover funções administrativas, desde que não sejam ultrapassados os limites municipais de jurisdição, a descentralização política se revela quando fossem atribuídas funções legislativas aos órgãos locais, isto é, com a deliberação de órgãos competentes para editar leis de eficácia local (BASTOS, 1995a, p. 107).

\footnotetext{
${ }^{18}$ Art. 34 da CFRB/88. A União não intervirá nos Estados nem no Distrito Federal, exceto para: I - manter a integridade nacional (...).

${ }^{19}$ Segundo Celso Ribeiro Bastos: "a descentralização pode assumir feição horizontal ou vertical. Por meio da horizontal, cria-se a denominada administração indireta, composta por autarquias, fundações e empresas estatais; e, pela vertical, dá-se origem a circunscrições territoriais, denominadas de municípios, províncias, regiões, departamentos ou comunas" (BASTOS, 1995a, p. 106).

Revista de Direito Urbanístico, Cidade e Alteridade | e-ISSN: 2525-989X | Salvador | v. 4 | n. 1 | p. 19 - 38 | 
Tudo se resume em um processo de redemocratização da estrutura do poder. Aos municípios foi deixado o processo de execução. Passando, inclusive, a arcar com parte do financiamento destas políticas, em particular no setor da educação fundamental e na saúde (AIETA; GARCIA; LEITE, 2016, p. 19).

Entende-se por essencial a compreensão de dois aspectos centrais que são consequências da reorganização estrutural de poder no federalismo brasileiro: a autonomia e a participação. Para a primeira, a Constituição Federal de 1988 asseverou que os governos municipais possuem quatro capacidades: a) de auto-organização, através de lei orgânica elaborada e promulgada por sua Câmara de Vereadores, não havendo qualquer interferência legislativa estadual ou federal; b) de autogoverno, que neste caso é ministrado pelo prefeito e também pelos vereadores elegidos para tanto través da via ordinária (votação direta e secreta); c) de auto legislação sobre matéria de interesse local e também sobre outros tipos, desde que suplementar e concorrente; e, por último, d) de auto administração, de maneira que a arrecadação de tributos municipais é de sua competência, aplicando suas receitas, elaborando seus planejamentos econômicos e prestando serviços públicos à sociedade local.

Quanto à segunda, é preciso esclarecer que a participação é fundamento da valoração da vontade política dos entes federais, ou seja, somente dessa forma se alcançará a soberania de fato de uma Federação. Ainda há outro sentido que eclode deste aspecto. Saber que há participação é discutir sobre cooperação e ampliação da autonomia entre os entes, autonomia esta que advém de um mandamento constitucional que divide as competências considerando a vontade de todos os entes em sua formação ${ }^{20}$ (AIETA; GARCIA; LEITE, 2016, p. 19-20).

A conclusão a que chegamos, por uma análise de lógica factual, é de que a ascensão municipal na qualidade de ente federativo foi vista como possível resposta à crise urbana do país posto que o "melhor combate" se faz daquele que atingiria a os problemas em sua matriz - a comunidade segundo sua localidade específica.

Logo vieram expressas na Constituição Federal as responsabilidades que recairiam sobre os governos municipais. A sua competência passou, portanto, a englobar: a)

20 "O princípio geral que delineia a repartição de competência entre as entidades componentes do Estado Federal é o da 'predominância do interesse', que se manifesta nas afirmações de que à União caberão as matérias de "interesse geral", aos estados, as de 'predominante interesse regional'; e, aos municípios, aqueles 'assuntos de interesse local',' (AIETA; GARCIA; LEITE, 2016, p. 22).

Revista de Direito Urbanístico, Cidade e Alteridade | e-ISSN: 2525-989X | Salvador | v. 4 | n. 1 | p. 19 - 38 | 
organização e prestação, diretamente ou sob regime de concessão ou permissão; b) manutenção e prestação de programas sobre educação infantil e de ensino fundamental com auxílio financeiro da União e dos Estado-membro; c)serviços de atendimento à saúde; d) promoção, naquilo que lhe for pertinente, o devido ordenamento territorial local, partindo de planejamentos e controle de uso, parcelamento e da ocupação do solo urbano; e e) ao dever de dispensar proteção ao patrimônio histórico-cultural local (AIETA; GARCIA; LEITE, 2016, p. 20).

Os constituintes coadunavam com a perspectiva de que a cooperação entre estes entes federativos traria mudanças que aquele período demandava em todos os aspectos, principalmente sociais, em conjunto com a descentralização sob vista do princípio da subsidiariedade, conforme é previsto na Constituição Alemã (AIETA; GARCIA; LEITE, 2016, p. 21).

Portanto, é conclusivo que os verdadeiros agentes propulsores destas mudanças não são os governos, mas na verdade as cidades, os municípios, os bairros, por meio de ações conjuntas com a participação da comunidade local (AIETA, 2016, p. 1622). Algumas questões atuais defendidas por outros autores contemporâneos como as modificações sofridas na autonomia municipal ou a sua "Recentralização" são questões que não cabem ser discutidas aqui por demandar outra pesquisa extensa. Todavia, podemos perceber que o planejamento da ascensão municipal a partir de 1988 se tornou um importante instrumento que traria consigo uma maior convivência harmônica das comunidades locais, promovendo o bem-estar de todos, proteção às diferenças culturais, étnicas, religiosas, linguísticas, políticas, e etc. Isso se deve ao fator de proximidade dos municípios com os próprios cidadãos, destacando a importância de ser atribuído a estes governos autonomia gestacional nos mais diversos aspectos.

\section{3- O REGIME "GREEN ECONOMY" E SUA INLFUÊNCIA NA ATUAL} CONJUNTURA URBANA BRASILEIRA.

Vivenciamos uma época onde a busca pela plena harmonização social, respeito à diversidade cultural e a promoção do que é justo de forma difusa são primazias políticas. A abordagem deste tema, que por tempos se viu menosprezado e refém frente ideologias avassaladoras de uma vida digna mundial, hoje conta com princípios fundamentais 
propulsores de uma sustentabilidade urbano-social sem olhar a quem. As cidades - diga-se um direito digno de convivência social e habitação - deixam de ser um direito de poucos para revestir-se de uma manta mais "humanizada".

Vânia Siciliano Aieta discursa sobre a progressão das cidades brasileiras para um modelo chamado "cidades humanas". A principal ideia aqui é de pontuar quais são as características de uma cidade inteligente. Essas cidades constituem um modelo que vem ganhando força dentro das políticas urbanas estrangeiras, especialmente nos governos europeus.

As cidades ganham o destaque nominal "inteligente" quando percebemos que suas ideologias pregam uma lavagem na estrutura sociocultural daqueles cidadãos, altera as suas relações com o Estado em prol de uma absoluta harmonização equânime. O princípio da Dignidade da Pessoa Humana ganha especial destaque frente às políticas segregacionistas de "higienização urbana".

Ao partirmos desta linha de pensamento o ponto final é a "Cidade Humana" 21 ". Afinal, o que vem a ser considerada uma cidade "humanizada"? A melhor definição objetiva é dada por Vânia Aieta ao classificá-la como uma organização sociocultural com infraestruturas modificadas visando aos residentes dos centros urbanos um novo ambiente de interação (AIETA, 2016, p. 1623).

Acontece que este modelo vem ganhando forças no cenário mundial. O fenômeno das cidades inteligentes é tão recente que os estudiosos ${ }^{22}$ ainda estão tecendo uma construção doutrinária.

\footnotetext{
${ }^{21}$ Vânia Siciliano Aieta define como causa da promoção das "Cidades Humanas" o fenômeno da globalização "que teve o condão de promover uma nova era de estreitamento das relações comerciais entre os países, auxiliado, sobretudo, pelo desenvolvimento tecnológico, o qual impactou de forma significativa grande parte das sociedades nacionais (...) as cidades experimentam uma formação social e governamental que pode se assemelhar a outras tentativas de uma idealização dos tempos da Grécia e Roma antigas (...)." (AIETA, 2016, p. 1623).

${ }^{22}$ Edmund Hussel (2000) é matemático e filósofo alemão que desenvolveu o método fenomenológico em sua obra "A ideia da Fenomenologia". Esta metodologia vem sendo a principal forma de estudo das implicações que tem as cidades inteligentes, partindo de um ambiente não pré-conceitual, analisando o fenômeno em si mesmo em dado espaço geográfico e sua repercussão em cada pessoa. O estudo parte da interpretação de múltiplas realidades a depender de quantas advier da análise proposta.
} 
É curioso saber que para Aristóteles ${ }^{23}$ a convivência conjunta que formava a polis estava ligada a noção de felicidade. Um lugar onde todos estão abrigados, protegidos, onde há relações correlacionadas paralelamente, um lugar onde todos conseguem satisfazer suas necessidades fundamentais, um lugar onde há plena agregação de individuais em prol do bem comum. É exatamente um lugar, descrito por Sócrates, aonde o homem encontraria sua felicidade. Tudo isso resume a política em uma descrição certa de que o homem não vivia apenas em prol de si mesmo, mas somente quando para coletividade. Aqui, a propriedade é vista como um benefício à coletividade. A cidade aqui retoma a essência de centro de convivência ${ }^{24}$ plena das pessoas.

Dessa forma, as cidades, por via de seus governadores, devem preconizar o desenvolvimento de um espaço de habitação dignamente possível a todos os seus cidadãos, elevando sua essência - cumprindo com sua função social e fundamental - dando habitação, assegurando direitos sociais iguais e proporcionais a todos, atendendo as necessidades humanas de forma digna para sua existência e também de felicidade (AIETA, 2016, p. 1626). A visão das cidades inteligentes não coaduna com o chamado declínio do espaço público, pelo contrário, promovem plena harmonização sociocultural e o respeito, por meio da integração comunitária, a diversidade cultural e ideológica.

Por exemplo, existe o problema da mobilidade urbana vivenciada na cidade do Rio de Janeiro. O resultado são pessoas estressadas, exaustas, no limite máximo de fadiga por conta de adversidades relacionadas ao transporte (AIETA, 2016, p. 1627). Isso nos remonta novamente a ideia de convergir esforços na busca da proteção de interesses sociais e de difundir a ideia de felicidade aristotélica. Afinal, o que nos leva a crer que no Brasil vivenciamos uma implantação de "cidades humanizadas"?

A resposta que temos é essa: desde o processo da redemocratização da política urbana, da Neoconstitucionalização brasileira e dos novos paradigmas urbanos legalmente previstos em conjunto com à promoção dos princípios fundamentais deveriam consolidar uma

\footnotetext{
${ }^{23} \mathrm{O}$ filósofo Aristóteles, desde épocas em Atenas, estudou o homem como um animal político destinado a viver em sociedade. Devemos pontuar que a noção de política aqui, à época do filósofo, é diferente dos parâmetros atuais. Política era viver em função da coletividade, ou seja, em prol de todos os cidadãos (MOTA; TORRES, 2009, p. 157).

24 “A cidade é o lugar para nós e para aqueles que virão depois de nós; o lugar para os que continuarão lutando para fazer com que nos sintamos em casa neste mundo. A cidade traz o sentimento de estarmos em casa" (BERMAN, 2007, p. 57)

Revista de Direito Urbanístico, Cidade e Alteridade | e-ISSN: 2525-989X | Salvador | v. 4 | n. 1 | p. 19 - 38 | 
realidade ainda equidistante. Tudo isso envolve a noção de cidade sustentável ${ }^{25}$, pois sabemos que as cidades inteligentes modificam as relações entre cidadãos e as instituições, a economia e, consequentemente, entre os próprios indivíduos (AIETA, 2016, p. 1629).

A partir desse ponto ganha destaque o regime da economia verde (green economy policy). A palavra de origem anglo-saxônica green objetiva abraçar tudo que contribui para uma melhora da sustentabilidade em aspectos mais amplos possíveis. É uma política que ainda é mais visada pelos países europeus. Existem também os denominados de green buldings, são construções que tendem a reduzir todo tipo de impacto ambiental, assim como da mesma forma se fala muito sobre a green economy como nova proposta de promover o desenvolvimento socioeconômico com impactos reduzidos. Há uma forte recepção de tudo que se mostra como alternativo, sustentável, green e smart nos modelos urbanos estrangeiros.

O regime green economy vai mais além, visa proporcionar uma alternativa de pleno desenvolvimento urbano sustentável. Apesar de se aproximar a promoção de uma economia ecologicamente equilibrada, ele tem um forte viés político urbano e social. Segundo UNEP Programa das Nações Unidas para o Ambiente - em seu relatório de 2011 é esclarecido que "para ser green, uma economia não só deve ser eficiente, mas também justa. A equidade implica reconhecer as dimensões de equidade a nível mundial e em todo o país, particularmente ao assegurar uma transição justa para uma economia com baixo carbono, eficiente em termos de recursos, instrumentos e inclusão social”.

A Constituição Federal de 1988 traz em seu dispositivo $225^{26}$ o direito ao meio ambiente ecologicamente equilibrado, indispensável à qualidade de vida do ser humano. $\mathrm{Na}$ realidade, vemos aqui que o constituinte buscou uma subversão de mentalidades, portanto, possibilitando uma futura vivencia dos benefícios de uma "Cidade Humana". Não obstante, o Estatuto da Cidade (lei n ${ }^{\circ} 10.257 / 01$ ) carrega consigo diversos instrumentos coadunantes com

\footnotetext{
${ }^{25} \mathrm{O}$ tema sustentabilidade se refere principalmente à questão ambiental, contudo, não modo exclusivo. A questão ambiental está associada a um problema econômico e também político. Existem três elementos que influem nas mudanças de uma cidade: a) elemento econômico; b) elemento ambiental; c) elemento social. Todos se encontram associados e, apesar de cada um desempenhar um papel independente, estão ligados entre si. Dessa forma a noção de cidade sustentável tem nítida relação à adoção de regimes voltados à melhoria da qualidade de vida da população, desenvolvimento econômico e a preservação do meio ambiente equilibrado (AIETA, 2016, p. 1629-1630).

${ }^{26}$ Art. 225 da CFRB/88. Todos têm direito ao meio ambiente ecologicamente equilibrado, bem de uso comum do povo e essencial à sadia qualidade de vida, impondo-se ao Poder Público e à coletividade o dever de defendê-lo e preservá- lo para as presentes e futuras gerações.

Revista de Direito Urbanístico, Cidade e Alteridade | e-ISSN: 2525-989X | Salvador | v. 4 | n. 1 | p. 19 - 38 | Jan/Jun. 2018
} 
a promoção da política de desenvolvimento urbano sustentável e com a ordenança harmônica de convivência.

O fato é que a própria Constituição garante de forma explícita uma política de desenvolvimento urbano com função social, isto é, com a possibilidade de haver uma reorganização/transformação em benefício do coletivo. Para tanto, compõe como um dos princípios trazidos pelo Estatuto da Cidade a participação social gestacional nas questões urbanas trabalhadas pelo Estado. Mais uma vez o plano teórico legislativo caminha para a consolidação da modalidade "Cidade Humana".

Trazer o dinamismo urbano para dentro da vivência social em conjunto com a participação social na tomada de decisão, fiscalização, e etc., faz nascer o chamado organismo vivo social (AIETA, 2016, p. 1628). A transição, pregado pelo regime do green economy, tende a nos direcionar para um modelo totalmente inclusivo dentro das cidades inteligentes $\left(\right.$ smart city $\left.^{27}\right)$.

A forte caraterística apresentada pelas cidades inteligentes é justamente a cooperação, fazendo com que os cidadãos se empenhem a participar de modo direto das decisões políticas daquela determinada localidade. A passagem de uma modalidade tradicional para um ambiente sustentável e inclusivo vem sendo possível em diversos outros governos locais, demanda principalmente não uma espécie de renúncia, mas sim de escolha das pessoas e das instituições. É escolha de aceitar a transformação e partir do extremo individual para promover o interesse coletivo em primeiro plano.

Em suma, desde a promulgação da Constituição Federal de 1988 o Brasil possui estreita ligação normativa com a política do green economy e também do modelo das cidades inteligentes. Os novos parâmetros urbanos elencados pela Carta Magna e pelo Estatuto da Cidade suscitam um questionamento - seriam tais instrumentos causas ou consequências

\footnotetext{
${ }^{27}$ A temática sobre a smart city pode ainda apresentar-se em primeiro plano de forma complexa, contudo, reforça a perspectiva que traz o aspecto de organismo vivo e funcionalizante dentro das cidades onde percebemos que tanto pessoas quanto o Estado trabalham em harmonia e testemunha uma plena inclusão social em benefício coletivo. Este tema remonta a qualquer tipo de transformação, seja ela econômica, social, ambiental e com inovações tecnológicas. Propõe um futuro aonde não e conseguira distinguir entre o formal e o funcional devido ambos estarem perfeitamente conectados. Para tanto, alguns exemplos são destacados como: cidades da Europa aonde a qualidade de vida encontra-se ligada a instrumentos alternativos sustentáveis, também conhecidos como cidades solares, cidades verdes, transition town, cidades resilientes, dentre outras. (AIETA, 2016, p. 1631-1639).

Revista de Direito Urbanístico, Cidade e Alteridade | e-ISSN: 2525-989X | Salvador | v. 4 | n. 1 | p. 19 - 38 | 
desses supostos regimes descritos? A questão gera certa dúvida quando passamos a contrastar o plano teórico com a realidade factual.

Muito embora ainda subsistam diversas situações que precisam ainda de maiores esclarecimentos, persistem casos que demandam maior atenção para que de fato se garanta a plenitude harmônica de convivência social, de respeito à diversidade e de igualdade para todos. Persistem divergências dentro da administração dos Municípios. O fato de o Brasil estar caminhando para o modelo das cidades inteligentes requer muitas transformações ainda, principalmente no plano prático. Ganha relevância a presente discussão quando é trazida a visão crítica da realidade para que um dia possamos observar a plenitude da Dignidade da Pessoa Humana disposta na nossa Constituição Federal. E assim, buscar a homogeneização de cidades sustentáveis e guardiãs dos direitos sociais e fundamentais dentro do nosso País.

\section{CONSIDERAÇÕES FINAIS}

Verifica-se a necessidade da adequação do espaço, como meio de alcançarmos o ajuste básico para a formação das futuras gerações. Neste sentido, demonstra-se no presente artigo a relevância do Ministério das Cidades, em cooperação de escopos como o poder municipal, em garantir àquilo necessário para a inserção da criança e do adolescente no espaço público convivacional, através de prestações positivas que visem oferecer, ao menos, a quantidade mínima de direitos sociais, sem aos quais os mesmos não têm condições de afastar o atual quadro de segregação socioespacial.

A questão envolvendo a tutela do direito à cidade, portanto, está inegavelmente baseada na obrigatoriedade do Município em efetivar soluções voltadas para a revitalização e a readequação dos espaços, buscando resguardar o direito da criança e do adolescente à cidade. Nesta empreitada devemos nos valer das normas urbanísticas, seja de origem constitucional (por meio dos artigos 182 e 183, ambos da CF/88), ou de estirpe infraconstitucional, como o Estatuto da Cidade (lei $n^{0} 10.257 / 01$ ), no intuito de alcançar o pleno desenvolvimento das funções sociais da cidade. O Plano Diretor, no contexto, está inserido como o principal instrumento que fornece ao poder público municipal instrumentos para o desenvolvimento urbano sustentável e melhoria da qualidade de vida de todos os cidadãos, em especial das crianças e dos adolescentes, que merecem distinta atenção do Estado. 
A criação do Ministério da Cidade, em cooperação de desígnios com o Município, vem ao encontro da perspectiva de garantir o "direito à cidade", por meio do fomento de uma política nacional de desenvolvimento urbano, que visa garantir o adequado suporte institucional à efetiva implementação do Estatuto da Cidade. Neste sentido, a consolidação do Ministério das Cidades é um marco na reestruturação da política urbana nacional, ocupando o vazio institucional que retirava o governo federal da discussão sobre a política urbana e o destino das cidades.

Transmuta-se, portanto, o antigo paradigma da elaboração de planos e projetos a partir dos níveis superiores da representação política, de viés tecnocrático e excludente da participação local e popular, pela primazia do planejamento municipal, baseado na gestão democrática, em cooperação com os demais entes da federação. Não obstante a imprescindível atuação do gestor municipal, o Governo Federal, por meio do Ministério da Cidade - que visa fomentar políticas públicas centradas na melhoria das condições de habitação, saneamento ambiental (água, esgoto, drenagem e coleta e destinação de resíduos sólidos) e mobilidade urbana (trânsito) - passa também a ter destacado papel na superação do atual quadro segregacionista, ao conferir diretrizes e bases institucionais para a melhoria das condições condignas de utilização do espaço público.

Com efeito, ao destacar que a política urbana no Brasil depende essencialmente de um esforço de cooperação federativa - observando o primado da gestão democrática das cidades - é incontroverso que o planejamento das cidades constitui um ato estruturado de mobilização entre os entes da federação e os vários segmentos da sociedade. Contribui-se, com isso, para a boa governança, ao destacar a legitimidade e relevância do Ministério das Cidades na elaboração de diretrizes gerais e suporte institucional que promova a inclusão socioespacial da criança e do adolescente, por meio da articulação, implantação e implementação - em parceria com todas as esferas do Poder Público e com a sociedade - de programas e ações destinados a universalizar o acesso da população à habitação digna, ao saneamento ambiental e à mobilidade, que é dada pela racionalização do trânsito e transporte público.

Em suma, a presente discussão transpareceu carrear questões hoje que estão sendo vivenciadas, implantas e executadas pelos ditames da constitucionalização contemporânea. Por outro lado, justificamos que a realidade pragmática, isto é, a transposição do plano teórico para a realidade, carece ainda de muito trabalho e esforço (digamos que não apenas do próprio Poder Público, mas em complemento com ações e reivindicações da sociedade participativa). 
Não deixa de ser efeitos de um suposto sistema da green economy, como é vivenciada por alguns países da Europa. A grande questão é que hoje caminhos para a construção de uma democracia mais que participativa, um ambiente político e administrativo mais inclusivo, solidário e multifuncional. $\mathrm{O}$ respeito pela diversidade, pela heterogeneidade, o amor ao próximo, são virtudes que caracterizam os indivíduos como cidadãos de fato e de direito, construindo uma cidade inteligente que promove essencialmente o harmônico convívio comunitário.

\section{REFERÊNCIAS BIBLIOGRÁFICAS}

AIETA, Vânia Siciliano. Cidade inteligentes e o pacto dos prefeitos: uma proposta de inclusão dos cidadãos rumo à ideia de 'cidade humana'. Revista de Direito da Cidade, v. 8, $n^{\circ} 4,2016$.

AIETA, Vânia, GARCIA, Maria, LEITE, Flávia. (coord.) Cadernos de Direito da Cidade:

Estudos em homenagem à Professora Maria Garcia. Série III. Rio de Janeiro: Lumen Juris, 2016.

BARROSO, Luís Roberto. Curso de Direito Constitucional Contemporâneo: os conceitos fundamentais e a construção do novo modelo, 5. ed. São Paulo: Saraiva, 2015.

BASTOS, Celso Ribeiro. Curso de Teoria do Estado e Ciência Política. 3. ed. São Paulo: Saraiva, 1995a.

Curso de direito constitucional. São Paulo: Saraiva, 1989

BASTOS, Celso Ribeiro. Por uma nova Federação. São Paulo: Editora Revista dos Tribunais, $1995 \mathrm{~b}$.

BASTOS, Celso Ribeiro. Curso de Direito Constitucional. 11. ed. São Paulo: Saraiva, 1989.

BERMAN, Marshall. Tudo o que é sólido desmancha no ar. São Paulo: Companhia das Letras, 2007.

BONAVIDES, Paulo. Curso de Direito Constitucional. 6. ed. São Paulo: Malheiros, 1996.

BRASIL, Constituição da República Federativa do Brasil de 1988, disponível em <http://www.planalto.gov.br/ccivil_03/constituicao/constituicaocompilado.htm>. Acessado em 21/02/2018.

CALDEIRA, Teresa P. A cidade de muros. São Paulo: Cia das Letras, 2000.

CASTRO, José Nilo. Direito municipal positivo, Belo Horizonte: Del Rey, 2006

Revista de Direito Urbanístico, Cidade e Alteridade | e-ISSN: 2525-989X | Salvador | v. 4 | n. 1 | p. 19 - 38 | 
CAVALLAZZI, Rosângela Lunardelli, O Estatuto Epistemológico do Direito Urbanístico Brasileiro: Possibilidades e Obstáculos na Tutela do Direito à Cidade, in Revistas Magister de Direito Ambiental e Urbanístico, 13ª edição, Ago/Set-2007. Porto Alegre: Editora Magister, 2007

COSTA, Nelson Nery. Curso de Direito Municipal Brasileiro. 2. ed. Rio de Janeiro: Forense, 2000.

DIKEN, B. e LAUSTSEN, C. B. Zone of Indistinction: Security, Terror and Bare Life, in Space and Culture, vol. 5, n. 3, 2002.

ELLIN, Nan. Fear and City Building, in The Hedgehog Review, vol 5, n. 3, 2003

FERNANDES, Edésio. Direito Urbanístico e Política Urbana no Brasil: uma introdução, in Direito Urbanístico e Política Urbana no Brasil. Belo Horizonte: Del Rey, 2000

FILHO, Nagib Staibi. Direito Constitucional, São Paulo: Forense, 2004.

GADAMER, Hans-Georg. Verdade e Método. Petrópolis, Vozes, 1997

HUSSERL, Edmund. A ideia da fenomenologia. Trad. Artur Morão. Lisboa: Editora 70, 2000 .

JACOBS, Jane. Morte e Vida nas Grandes Cidades. São Paulo: Martins Fontes, 2003

MARICATO, Erminia Terezinha Menon. Entrevista concedida à Revista aU. Disponível em: <http://www.revistaau.com.br/arquitetura-urbanismo/156/imprime44395.asp>. Acesso em: 30 jan. 2009

MEIRELLES, Hely Lopes. Direito municipal brasileiro. São Paulo: Malheiros Editores, 1998

MELO, Marcus André B.C. de. O município na federação brasileira e a questão da autonomia. In: SUBSIDIARIEDADE e Fortalecimento do Poder Local - Debates. Fundação Konrad Adenauer Stiftung - Representação no Brasil. São Paulo: Centro de Estudos, 1999, n. 6.

MORAES, Alexandre de. Direito Constitucional. 23. ed. São Paulo: Atlas, 2008.

MOTA, Maurício; TORRES, Marcos Alcino de Azevedo. Transformações do direito de propriedade privada, Rio de Janeiro: Elsevier, 2009.

SILVA, José Afonso da. Curso de direito constitucional positivo. São Paulo: Malheiros Editores, 2007.

UNEP, 2011, Towards a Green Economy: Pathways to Sustainable Development and Poverty Eradication, disponível em <www.unep.org/greeneconomy>. Acessado em 22/02/2018.

ZYGMUNT, Bauman. Confiança e medo na cidade: tradução Eliana Aguiar. Rio de Janeiro: Jorge Zahar Ed, 2009

Revista de Direito Urbanístico, Cidade e Alteridade | e-ISSN: 2525-989X | Salvador | v. 4 | n. 1 | p. 19 - 38 | 